\title{
Definisi Sistem Portal Pengetahuan Dalam Pemerintahan Berdasarkan Pendekatan Modifikasi Soft System Methodology dan Hermeneutic
}

Knowledge

Management

System

\author{
Wahyu Indra Satria, Yanto Hermawan dan M. Figo Haffidz Akbar \\ Program Studi Sistem Informasi, Institut Bisnis dan Informatika Kesatuan \\ E-Mail: wahyuindrasatria@ibik.ac.id
}

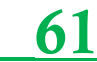

Submitted: JANUARI 2021

Accepted: JULI 2021

\begin{abstract}
A state government can implement a knowledge portal-based e-Government system to properly accommodate knowledge management activities. This is also useful in minimizing knowledge gaps, loss of knowledge, and wasted knowledge in the operational process of government when providing services to the community. This is intended so that the government can massively, effectively and efficiently carry out public services to the community. The research hypothesis is that the existence of an e-Government system based on a knowledge portal can assist the government in carrying out knowledge management activities in every operational activity with the aim of helping carry out public service activities more effectively and efficiently. Referring to this description, the focus of the research carried out is to discuss and find a structured scientific formal definition of the knowledge portal system in government based on a modified approach of soft system methodology and hermeneutics. The object of the research will be carried out at the Indonesian state government agencies with the hope of meeting the research objectives, namely finding a structured scientific formal definition of the knowledge portal system within a government.
\end{abstract}

Keywords: e-govenrment, knowledge management, knowledge portal system.

\begin{abstract}
ABSTRAK
Suatu pemerintahan negara dapat menerapkan sistem e-Government berbasis portal pengetahuan untuk mengakomodir dengan baik aktivitas manajemen pengetahuan. Hal ini juga bermanfaat meminimalisir kesenjangan pengetahuan, kehilangan pengetahuan, dan kesia-siaan pengetahuan dalam proses operasional pemerintahan ketika melakukan pelayanan terhadap masyarakat. Hal ini dimaksudkan agar pemerintah dapat secara massif, efektif dan efisien dalam melakukan pelayanan publik masyarakat. Hipotesis penelitian yang dilakukan adalah dengan adanya sistem e-Government berbasis portal pengetahuan dapat membantu pemerintah dalam melakukan aktivitas manajemen pengetahuan pada setiap kegiatan operasional dengan tujuan membantu menjalankan kegiatan pelayanan publik lebih efektif dan efisien. Mengacu pada penjabaran tersebut maka fokus penelitian yang dilakukan adalah membahas dan menemukan definisi formal ilmiah terstruktur dari sistem portal pengetahuan dalam pemerintahan berdasarkan pendekatan modifikasi soft system methodology dan hermeneutics. Objek penelitian akan dilakukan pada dinas-dinas pemerintahan Negara Indonesia dengan harapan dapat memenuhi tujuan penelitian yaitu menemukan definisi formal ilmiah terstruktur dari sistem portal pengetahuan di dalam suatu pemerintahan.
\end{abstract}

Kata Kunci: e-govenrment, manajemen pengetahuan, sistem portal pengetahuan.

\section{JIKES}

\section{PENDAHULUAN}

Pemerintah Negara Republik Indonesia memiliki tugas melakukan pelayanan prima terhadap masyarakat. Salah satu aktivitas yang berguna dalam melakukan pelayanan

Jurnal Informatika Kesatuan Vol. 1 No. 1,2021 page. $61-70$ IBI Kesatuan
ISSN xxxx $-\mathrm{xxxx}$ DOI: $10.37641 /$ jikes.v1i1.518 
Knowledge Management System

prima tersebut adalah dengan adanya kegiatan manajemen pengetahuan. Berdasarkan Peraturan Menteri Negara Pendayagunaan Aparatur Negara dan Reformasi Birokrasi Nomor 14 Tahun 2011, disebutkan bahwa "Kementrian/Lembaga dan Pemerintah Daerah untuk berpartisipasi aktif dalam berbagi pengetahuan yang dapat dimanfaatkan dalam perumusan kebijakan dan benchmarking pelaksanaan reformasi birokrasi". Disebutkan juga bahwa sistem manajemen pengetahuan adalah "Sistem (umumnya berbasis teknologi informasi) digunakan untuk melakukan pengelolaan atas pengetahuan pada tiap tahapan, baik saat perolehan, penyimpanan, pengambilan kembali, pemanfaatan maupun penyempurnaannya". Manajemen pengetahuan dapat diartikan sebagai tindakan dalam mendapatkan sumber pengetahuan, dengan creation, sharing, dan leveraging (memanfaatkan) gabungan pengetahuan (Becerra 2015). Sedangkan pengertian representasi pengetahuan adalah bagaimana "menyimpan" pengetahuan ke dalam suatu media dalam hal ini adalah komputer (Bone 2005).

Kegiatan manajemen pengetahuan pada organisasi pemerintahan dapat terhambat apabila terjadi kendala. Contohnya adalah aturan rotasi mutasi Pegawai Negeri Sipil. Pada Undang-Undang Republik Indonesia Nomor 5 Tahun 2014 disebutkan "Setiap Pegawai Negeri Sipil (PNS) dapat dimutasi tugas dan/atau lokasi dalam 1 (satu) instansi pusat, antar instansi pusat, 1 (satu) instansi daerah, antar instansi daerah, antar instansi pusat dan instansi daerah, dan ke perwakilan Negara Kesatuan Republik Indonesia diluar Negeri". Hal tersebut memunculkan hambatan dalam aktivitas manjemen pengetahuan untuk melakukan pelayanan prima terhadap masyarakat. Dengan peraturan mutasi, memunculkan kesenjangan pengetahuan, kehilangan pengetahuan, dan kesia-siaan pengetahuan. Hal lain yang menghambat terjadinya akitivitas manajemen pengetahuan yaitu perbedaan persepsi antara para pegawai beserta masyarakat akan undang-undang, aturan, regulasi maupun prosedur-prosedur yang berlaku untuk pemenuhan hak dan kewajiban pegawai beserta masyarakat dalam kegiatan operasional pelayanan yang berlangsung dipemerintahan.

Pemerintah dapat menerapkan sistem e-Government berbasis portal pengetahuan untuk mengakomodir kegiatan manajemen pengetahuan beserta meminimalisir kesenjangan pengetahuan, kehilangan pengetahuan, dan kesia-siaan pengetahuan dalam proses operasional pemerintahan ketika melakukan pelayanan publik. Hal ini dimaksudkan agar pemerintah dapat secara massif, efektif dan efisien dalam melakukan pelayanan publik. e-Government sendiri didefinisikan sebagai penggunaan teknologi informasi dan komunikasi (TIK) terutama internet dan world wide web untuk meningkatkan efisiensi, biaya dan kualitas informasi serta layanan pemerintah yang diberikan kepada pemangku kepentingan negara yaitu para warga negara, para pelaku bisnis, para pegawai serta instansi pemerintah terkait.

Penerimaan dan keberhasilan e-Government bergantung pada keinginan warga negara untuk menerapkan teknologi inovatif ini. Hal ini menyebabkan banyak pemerintah di seluruh dunia saat ini menderita rendahnya tingkat adopsi layanan e-Government oleh warga negaranya (EIKheshin 2016). Hipotesis penelitian yang dilakukan adalah dengan adanya sistem e-Government berbasis portal pengetahuan dapat membantu pemerintah dalam melakukan aktivitas manajemen pengetahuan pada setiap kegiatan operasional yang dilakukan agar dapat membantu menjalankan kegiatan pelayanan publik lebih efektif dan efisien. Mengacu pada penjabaran tersebut, maka fokus penelitian yang dilakukan adalah meneliti dan menemukan definisi formal ilmiah terstruktur dari sistem portal pengetahuan dalam suatu pemerintahan negara berdasarkan pendekatan modifikasi soft system methodology dan hermeneutics. Objek penelitian dilakukan pada dinas-dinas pemerintahan di Indonesia dengan harapan dapat memenuhi tujuan penelitian yaitu menemukan definisi formal ilmiah terstruktur dari sistem portal pengetahuan dalam suatu pemerintahan negara.

\section{Manajemen Pengetahuan, Representasi Pengetahuan, dan e-Government}

Manajemen Pengetahuan adalah tindakan dalam mendapatkan sumber pengetahuan, dengan creation, sharing, dan leveraging (memanfaatkan) gabungan pengetahuan (Becerra 
2015). Sedangkan pengertian Representasi pengetahuan adalah bagaimana "menyimpan" pengetahuan tersebut ke dalam komputer (Bone 2005). e-Government sendiri didefinisikan sebagai penggunaan teknologi informasi dan komunikasi (TIK) terutama internet dan world wide web untuk meningkatkan efisiensi, biaya dan kualitas informasi serta layanan pemerintah yang diberikan kepada para pemangku kepentigan/stakeholder Negara yaitu para warga negara, para pelaku bisnis, para pegawai serta instansi pemerintah lainnya. Penerimaan dan keberhasilan e-Government sangatlah bergantung pada keinginan warga negara untuk menerapkan teknologi yang sangat inovatif ini (EIKheshin, 2016).

\section{Sistem Manajemen Pengetahuan dan Sistem Portal Pengetahuan}

Sistem manajemen pengetahuan bertujuan mengelola pengetahuan dan penggunanya untuk menggunakan pengetahuan tersebut dalam menjalankan tugas organisasinya. Dikenal sebagai sistem berbasis teknologi informasi yang digunakan dalam mendukung, mengembangkan serta meningkatkan aktivitas manajemen pengetahuan organisasi. Prosesnya sendiri bisa diaplikasikan di beberapa alat teknologi informasi. Sistem manajemen pengetahuan mengakomodasi beberapa alat dan teknologi untuk mengelola aset pengetahuan organisasi beserta proses manajemen pengetahuan yang selaras dengan proses bisnis organisasi. Sistem portal pengetahuan sendiri merupakan suatu bentuk sistem manajemen pengetahuan dengan berbasis web yang memiliki definisi serta tujuan sama dengan sistem manajemen pengetahuan (Cahyaningsih., et al 2016).

\section{Soft System Methodology}

Soft Systems Methodology (SSM) adalah sebuah pendekatan holistik di dalam melihat aspek-aspek riil dan konseptual di masyarakat. SSM melihat setiap yang terjadi sebagai Human Activity System karena serangkaian aktivitas manusia dapat disebut sebagai sebuah sistem (Hidayatullah 2011). Metodologi SSM telah banyak digunakan untuk memgembangkan konseptual model atas suatu sistem. Beberapa contoh diantaranya adalah (Ramadhan., et. al 2011), mengusulkan suatu metodologi untuk pengembangan sistem e-Government dengan mengkombinasikan Soft Systems Methodology (SSM) beserta Focus Group Discussion (FGD).

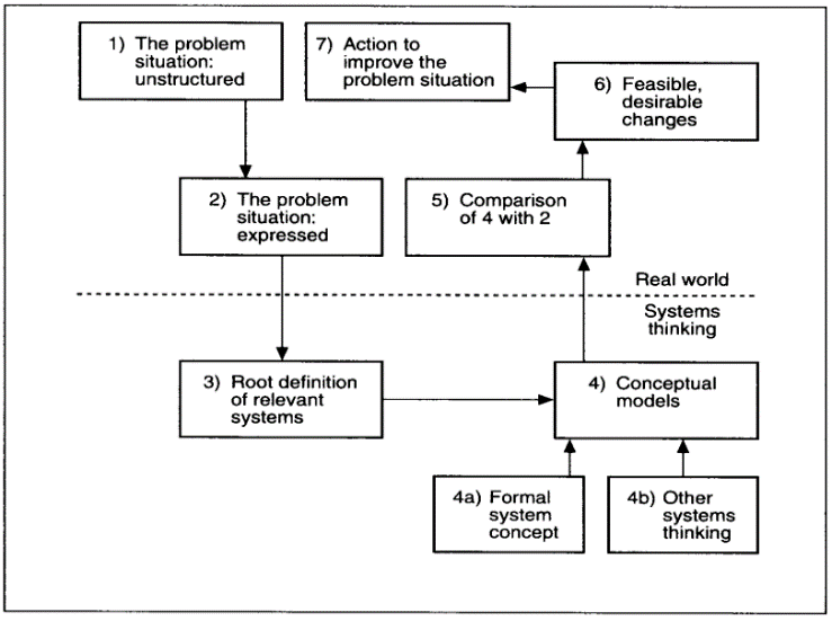

Gambar 1 Pendekatan Soft System Methodology

Dengan kombinasi SSM beserta FGD diharapkan bahwa interaksi sosial dari pemangku kepentingan/stakeholders dapat diakomodasi dengan baik, sehingga kegagalan dalam suatu pengembangan sistem e-Government dapat dikurangi. Penelitian (Razali., et. al 2010) mengusulkan integrasi antara soft systems methodology (SSM) beserta Design Science Research (DSR) untuk masa depan pengembangan, desain, dan solusi sosio-teknikal dalam knowledge sharing. Soft systems methodology (SSM) terdiri dari 7 (tujuh) langkah yang berkaitan satu sama lain yaitu:

1. Mengidentifikasi situasi masalah yang menjadi perhatian.

2. Mengekspresikan situasi masalah.
Knowledge

Management

System 
Knowledge Management System
3. Memformulasikan "root definition" dari sistem yang relevan.

4. Membangun model konseptual.

5. Membandingkan model konseptual dengan realita di dunia nyata.

6. Membuat perubahan pada model dengan mengakomodasi kepentingan beberapa aktor yang terlibat.

7. Melakukan berbagai aktivitas untuk menerapkan model dan memperbaiki masalah.

\section{Pendekatan Hermeneutic}

Pendekatan hermeneutic adalah suatu pendekatan interpretatif terhadap terjemahan teks, analisis teks, teks bacaan, dan sense data terutama berkaitan dengan makna teks. Pendekatan ini berhubungan erat dengan perspektif filosofis interpretivisme dari studi kualitatif, yang memungkinkan pemahaman dari pengalaman para ahli secara mendalam (Fauzie et al. 2016). Prinsip hermeneutic menunjukkan bahwa semua pemahaman manusia dicapai dengan iterasi antara pertimbangan makna saling ketergantungan, dari bagian-bagian dan keseluruhan bentuknya (Al-Hashedi et al. 2013), (Friston dan Frith 2015), (Jennings 2016), (Sarker dan Lee 2006). Proses penafsiran bergerak dari pemahaman awal tentang bagian-bagian tersebut ke keseluruhan konteks, kembali ke pemahaman yang lebih baik mengenai setiap bagian yang menjadi pembahasan tersebut (Ramadhan et al. 2012).



Gambar 2 Pendekatan Hermeneutic

Telah banyak peneliti yang melakukan riset terkait dengan topik sistem portal pengetahuan beserta manajemen pengetahuan. Berikut beberapa penelitian yang sudah dilakukan terkait dengan topik pembahasan yaitu penelitian (Ismail 2011) melakukan riset untuk mengetahui hambatan-hambatan apa saja yang terjadi pada aktivitas berbagi pengetahuan (knowledge sharing) dalam communities of practice lalu mengusulkan model untuk mendukung kebutuhan para software engineers ketika mendesain sebuah portal pengetahuan (kmowledge portal). Penelitian (Ribera 2011) mengusulkan portal aplikasi $e-$ Catalunya berbasis platform yang dipromosikan oleh pemerintah Catalunya untuk communities of practice secara virtual. Penelitian (Firdaus et al. 2012) mengusulkan model portal berbagi pengetahuan (knowledge sharing) yang dikembangkan pada communities of practice para dokter. Penelitian (Kwjnckw, 2010), membuktikan bahwa konsep dari communities of practice secara online menggunakan aplikasi portal web 2.0 diimplementasikan dengan baik dalam konteks sosial. Penelitian (Fauzie et al., 2016) mendapatkan definisi e-Hajj di Indonesia dengan pendekatan hermeneutic.

\section{METODE PENELITIAN}

Berikut akan dijabarkan fase-fase metode penelitian yang telah dilakukan. Fase satu yaitu studi literatur dimana pada tahap ini penulis melakukan studi literatur untuk menemukan latar belakang permasalahan penelitian. Dari berbagai literatur yang telah di review maka didapatkan hipotesis penelitian yang dilakukan. Hipotesis penelitiannya yaitu dengan pendekatan soft system methodology dan hermeneutic dapat membantu peneliti untuk memenuhi tujuan penelitian yaitu menemukan definisi formal ilmiah terstruktur 
dari sistem portal pengetahuan dalam Pemerintahan di Indonesia. Fase dua yaitu pengumpulan data dimana pada fase ini penulis mulai memasuki tahap 1 dan 2 dalam pendekatan soft system methodology yaitu identifikasi masalah dan ekspresi masalah. Penulis melakukan wawancara mendalam terhadap Para Ahli pada setiap Dinas-Dinas pemerintahan yang menjadi objek penelitian. Wawancara mendalam dimaksudkan agar penulis dapat membuat hasil identifikasi masalah dan ekspresi masalah (tahap 1 dan 2 dalam pendekatan soft system methodology) dari objek penelitian tersebut. Tahap ini dielaborasi dengan menggunakan rich picture dari masing-masing Dinas Pemerintahan yang menjadi objek penelitian.

Fase tiga yaitu analisis data dimana pada tahap ini penulis memasuki tahap 3 dalam pendekatan soft system methodology yaitu root definition (analisis CATWOE). Penulis melakukan elaborasi atas rich picture yang telah dikembangan dari masing-masing objek penelitian. Elaborasi rich picture tersebut kemudian dianalisis dengan hasil root definition (analisis CATWOE). Fase empat yaitu melakukan formulasi data dimana hasil dari analisis CATWOE kemudian diformulasikan dengan pendekatan hermeneutic. Formulasi dengan pendekatan hermeneutic ini merupakan formulasi dari data hasil analisis CATWOE beserta dengan hasil wawancara mendalam yang telah dilakukan dengan Para Ahli dari objek-objek penelitian yaitu dinas-dinas pemerintahan di Indonesia. Hal-hal ini dijadikan sebagai dasar dalam mencari definisi sistem portal pengetahuan dalam pemerintahan suatu negara. Fase lima yaitu penarikan kesimpulan dan saran dimana pada tahap ini penulis melakukan penarikan kesimpulan dari penelitian yang dilakukan beserta memberikan saran atas hasil penelitian.

\section{HASIL DAN PEMBAHASAN}

Berikut akan dijabarkan hasil-hasil beserta pembahasan atas penelitian yang telah dilakukan. Output/luaran hasil dan pembahasan ini di dapatkan dari pendekatan soft system methodology tahap 1 sampai 3 yang kemudian dilanjutkan dengan pendekatan hermeneutic. Alasan peneliti melakukan modifikasi penggunaan pendekatan soft system methodology dan hanya menggunakan sampai pada tahap ketiga dari pendekatan soft system methodology, dikarenakan fokus tujuan penelitian yaitu menemukan definisi formal ilmiah terstruktur dari sistem portal pengetahuan dalam Pemerintahan di Indonesia. Setelah mendapatkan hasil tahap 1 sampai 3 dari pendekatan soft system methodology tersebut, lalu hasil dari tahap 1 dan tahap 3 soft system methodology akan diformulasikan dengan pendekatan hermeneutic. Dimana hasil root definition dari wawancara mendalam kepada Para Ahli di dinas-dinas pemerintahan yang menjadi objek penelitian akan diformulasikan dengan pendekatan hermenutic agar proses penafsiran yang dilakukan bergerak dari pemahaman awal tentang bagian-bagian definisi sistem portal pengetahuan dalam Pemerintahan menjadi pemahaman lebih baik untuk menjadi pembahasan dan tujuan dari penelitian.

\section{Hasil Identifikasi Masalah (Soft System Methodology Tahap 1)}

Berikut adalah hasil identifikasi masalah berdasarkan wawancara mendalam dengan Para Ahli pada dinas-dinas pemerintahan di Indonesia. Output ini adalah hasil dari pendekatan soft system methodology tahap 1.

\begin{tabular}{|c|l|}
\hline No. & \multicolumn{1}{|c|}{ Hasil Identifikasi Masalah } \\
\hline 1. & Dibutuhkan persamaan pemahaman antar pegawai dalam penggunaan aplikasi. \\
\hline 2. & $\begin{array}{l}\text { Dibutuhkan sosialisasi atas pengetahuan baru penting bagi para pegawai dinas } \\
\text { pemerintahan seperti UU/aturan terbaru. }\end{array}$ \\
\hline 3. & $\begin{array}{l}\text { Dibutuhkan persamaan pemahaman/persepsi atas pengetahuan baru penting bagi para } \\
\text { pegawai dinas pemerintahan seperti UU/aturan terbaru. }\end{array}$ \\
\hline 4. & $\begin{array}{l}\text { Aktivitas manajemen pengetahuan dilakukan melalui kegiatan bimbingan teknis, } \\
\text { pelatihan, sampai tugas belajar. }\end{array}$ \\
\hline 5. & $\begin{array}{l}\text { Dibutuhkan sarana dan prasarana yang memadai dalam melakukan aktivitas } \\
\text { manajemen pengetahuan. }\end{array}$ \\
\hline 6. & Dibutuhkan SDM yang mumpuni melakukan manajemen pengetahuan. \\
\hline
\end{tabular}


Knowledge Management System

\begin{tabular}{|c|c|}
\hline 7. & $\begin{array}{l}\text { Pengetahuan yang tidak disebarkan secara efektif, sehingga menyebabkan kesenjangan } \\
\text { pengetahuan di antara para pegawai dinas pemerintahan. }\end{array}$ \\
\hline 8. & $\begin{array}{l}\text { Dibutuhkan adanya repositori pengetahuan pada sistem portal pengetahuan yang } \\
\text { dikembangkan sebagai media transisi pengetahuan, saat terjadi rotasi mutasi pegawai } \\
\text { baik pensiun maupun yang di mutasi di dalam dinas pemerintahan. }\end{array}$ \\
\hline 9. & $\begin{array}{l}\text { Dibutuhkan suatu sistem portal pengetahuan yang terintegrai antara seluruh dinas- } \\
\text { dinas pemerintahan. }\end{array}$ \\
\hline 10. & $\begin{array}{l}\text { Manajemen pengetahuan dilakukan oleh beberapa pegawai yang diutus untuk } \\
\text { mengikuti kegiatan Diklat. }\end{array}$ \\
\hline 11. & $\begin{array}{l}\text { Sistem portal pengetahuan dibutuhkan sebagai sarana untuk mendapatkan dan bertukar } \\
\text { pegnetahuan bagi para pegawai. }\end{array}$ \\
\hline 12. & $\begin{array}{l}\text { Dibutuhkan fitur komunikasi interaktif untuk sosialisasi terkait UU/regulasi baru bagi } \\
\text { para pegawai dinas pemerintahan dalam sistem portal pengetahuan. }\end{array}$ \\
\hline 13. & $\begin{array}{l}\text { Dibutuhkan adanya fitur komunikasi interaktif di antara para pegawai dinas } \\
\text { pemerintahan beserta dengan masyarakat. Hal ini dimaksudkan untuk mendapatkan } \\
\text { feedback interakitif antara sesama pegawai maupun dengan warga masyarakat. }\end{array}$ \\
\hline 14. & $\begin{array}{l}\text { Dibutuhkan sistem portal pengetahuan dengan fitur komunikasi interaktif untuk } \\
\text { berkomunikasi agar masyarakat bisa diarahkan langsung ke OPD-OPD terkait dengan } \\
\text { pelayanan yang diinginkan masyarakat. }\end{array}$ \\
\hline 15. & $\begin{array}{l}\text { Terjadi kesenjangan pengetahuan akibat adanya pegawai yang harus dimutasi ke dinas } \\
\text { lain ataupun yang pensiun. }\end{array}$ \\
\hline 16. & $\begin{array}{l}\text { Dibutuhkan sistem portal pengetahuan dengan fitur komunikasi secara tulisan (chat), } \\
\text { suara, maupun video conference untuk berkomunikasi antara seluruh dinas-dinas } \\
\text { pemerintahan secara real time pada jam kerja. }\end{array}$ \\
\hline 17. & $\begin{array}{l}\text { Dibutuhkan suatu sistem portal pengetahuan yang memiliki fitur komunikasi berbasis } \\
\text { intranet dan internet. }\end{array}$ \\
\hline 18. & Manajemen pengetahuan dilakukan melalui rapat bertingkat para pegawai. \\
\hline 19. & M untuk mengerjakan tupoksi yang besar. \\
\hline 20. & Keterbatasan waktu ketika melakukan rapat para pegawai. \\
\hline 21. & $\begin{array}{l}\text { Dikawatirkan adanya pekerjaan terbengkalai atau tercecer akibat tupoksi yang terlalu } \\
\text { besar karena tidak diimbangi dengan jumlah SDM yang memadai. }\end{array}$ \\
\hline 22. & $\begin{array}{l}\text { Manajemen pengetahuan dilakukan juga dengan kegiatan benchmarking ke dinas-dinas } \\
\text { pemerintahan di daerah-daerah lain. }\end{array}$ \\
\hline 23 & $\begin{array}{l}\text { Dibutuhkan suatu sistem portal pengetahuan dengan fitur untuk mengawasi, } \\
\text { memonitor, dan mengevaluasi kinerja para pegawai dinas pemerintahan. }\end{array}$ \\
\hline 24. & $\begin{array}{l}\text { Dibutuhkan sistem portal pengetahuan responsif yang kompatibel pada semua platform } \\
\text { (windows, IOS, LINUX, android dll). }\end{array}$ \\
\hline 25. & $\begin{array}{l}\text { Dibutuhkan sistem portal pengetahuan responsif yang kompatibel pada semua device } \\
\text { (gadget smartphone, laptop, dll). }\end{array}$ \\
\hline 26. & $\begin{array}{l}\text { Dibutuhkan sistem portal pengetahuan yang dapat dikustomisasi pengelompokan } \\
\text { menu-menunya sesuai dengan keinginan pemakai. }\end{array}$ \\
\hline 27. & $\begin{array}{l}\text { Portal merupakan gabungan kompleks dari beberapa web dengan banyak konten- } \\
\text { konten dinamis dan telah mengalami pengelompokan atas konten-konten tersebut. }\end{array}$ \\
\hline 28. & $\begin{array}{l}\text { Suatu portal harus memiliki sifat inter-operabilitas yaitu kapabilitas dari suatu software } \\
\text { atau sistem yang antar mukanya diungkapkan sepenuhnya untuk berinteraksi dan } \\
\text { berfungsi dengan produk atau sistem lain, kini atau di masa mendatang, tanpa batasan } \\
\text { akses atau implementasi, bisa mengelompokkan konten-konten pengetahuan, jadi tidak } \\
\text { terdiri dari web tersebut sendiri saja. }\end{array}$ \\
\hline 29. & $\begin{array}{l}\text { Sistem portal pengetahuan dibutuhkan dikarenakan sebagai identitas pengetahuan yang } \\
\text { valid terbarukan untuk di-implementasikan di-suatu pemerintahan negara. }\end{array}$ \\
\hline 30. & $\begin{array}{l}\text { Dibutuhkan sistem portal pengetahuan dalam kegiatan studi banding antar seluruh } \\
\text { dinas pemerintahan untuk melakukan manajemen pengetahuan. }\end{array}$ \\
\hline 31. & $\begin{array}{l}\text { Dibutuhkan sistem portal pengetahuan interaktif terintegrasi antar seluruh dinas } \\
\text { pemerintahan yang diakui oleh undang-undang negara. }\end{array}$ \\
\hline 32. & $\begin{array}{l}\text { Dibutuhkan sistem portal pengetahuan yang berpedoman pada kewajiban dari dinas } \\
\text { pemerintahan seperti keterbukaan informasi dan pengetahuan kepada publik. }\end{array}$ \\
\hline 33. & $\begin{array}{l}\text { Dibutuhkan sistem portal pengetahuan yang bisa memberikan pengetahuan kepada } \\
\text { masyarakat mengenai hal-hal apa saja yang dikerjakan oleh dinas-dinas pemerintahan, } \\
\text { beserta hasilnya seperti apa bagi warga masyarakat. }\end{array}$ \\
\hline
\end{tabular}




\begin{tabular}{|l|l|}
\hline 34. & Dibutuhkan sistem portal pegnetahuan dengan fitur pengaduan masyarakat. \\
\hline 35. & $\begin{array}{l}\text { Dibutuhkan sistem portal pengetahuan yang terintegrasi dengan seluruh dinas } \\
\text { pemerintahan di Indonesia. }\end{array}$ \\
\hline
\end{tabular}

\section{Ekspresi Masalah (Soft System Methodology Tahap 2)}

Berikut adalah ekspresi masalah hasil wawanacara wawancara mendalam dengan Para Ahli pada dinas-dinas pemerintahan di Indonesia. Hal ini dibutuhkan untuk menggambarkan situasi dengan rich picture dalam meng-capture berbagai persepsi yang dimiliki oleh Para Ahli sebagai narasumber objek penelitian. Output ini adalah hasil dari pendekatan soft system methodology tahap 2.

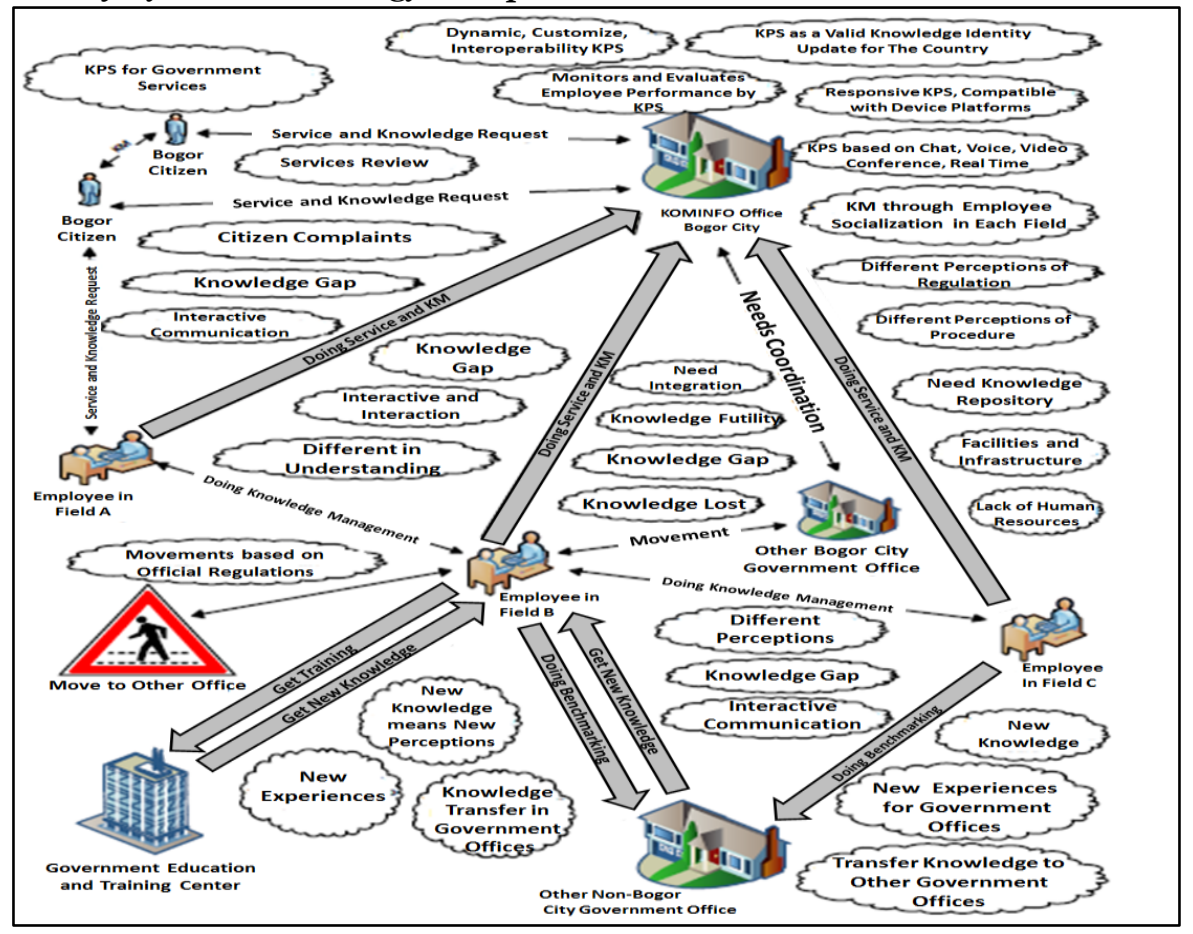

Gambar 3 Ekspresi Masalah Hasil Soft System Methodology Tahap 2

\section{Merumuskan Root Definition (Soft System Methodology Tahap 3)}

Berikut adalah perumusan root definition (analisis CATWOE) dalam menemukan pernyataan tujuan untuk meng-capture esensi penting dengan tujuan mendapatkan definisi formal ilmiah terstruktur dari sistem portal pengetahuan suatu pemerintahan negara. Output ini adalah hasil dari pendekatan soft system methodology tahap 3.

\begin{tabular}{|l|l|}
\hline $\mathbf{C}=$ Customer & Para pegawai pemerintahan dan masyarakat. \\
\hline $\mathbf{A}=$ Actor & Para pegawai pemerintahan. \\
\hline $\mathbf{T}=$ Transformation Process & $\begin{array}{l}\text { Mengubah kebutuhan para pegawai pemerintahan dan warga } \\
\text { masyarakat melakukan kegiatan manajemen pengetahuan } \\
\text { menjadi kebutuhan yang terpenuhi. }\end{array}$ \\
\hline $\mathbf{W}=$ Weltanschauung & $\begin{array}{l}\text { Sistem portal pengetahuan adalah suatu aplikasi berdasarkan } \\
\text { kombinasi kompleks dari beberapa website. Memiliki banyak } \\
\text { konten dinamis yang telah dikelompokkan dan terintegrasi } \\
\text { antar seluruh dinas pemerintahan. Memiliki fitur komunikasi } \\
\text { interaktif berbasis tulisan (chat), suara, mapun video conference } \\
\text { secara real time pada jam kerja. }\end{array}$ \\
\hline $\mathbf{O}=$ Owner & \begin{tabular}{l} 
Seluruh kantor pemerintahan. \\
\hline $\mathbf{E}=$ Environtment Constraints
\end{tabular} \\
$\begin{array}{l}\text { Birokrasi prosedur dalam implementasi sistem portal } \\
\text { pengetahuan, resistensi penggunaan, pengadaan anggaran, serta } \\
\text { sumber daya manusia. }\end{array}$ \\
\hline
\end{tabular}


Knowledge

Management

System

\section{Definisi Sistem Portal Pengetahuan dalam Pemerintahan}

Berikut adalah definisi formal ilmiah terstruktur dari sistem portal pengetahuan dalam suatu pemerintahan berdasarkan formulasi output soft system methodology tahap 3 dengan pendekatan hermeneutic. Penjabarannya adalah sebagai berikut.

"Sistem portal pengetahuan dalam pemerintahan adalah suatu aplikasi berbasis gabungan kompleks dari beberapa web, dengan banyak pengelompokkan konten-konten dinamis, yang terintegrasi antar seluruh dinas pemerintahan. Sistem portal pengetahuan dalam pemerintahan memiliki fitur komunikasi interaktif berbasis tulisan (chat), suara (voice call), mapun video conference secara real time pada jam kerja, sebagai repositori pengetahuan, dan notifikasi sosialisasi yang berguna bagi para pegawai dinas pemerintahan beserta warga masyarakat untuk melakukan manajemen pengetahuan. Tujuan sistem portal pengetahuan dalam pemerintahan adalah untuk meminimalisasi knowledge gap, knowledge lost dan knowledge futility antara para pegawai dinas pemerintahan, para pegawai dinas pemerintahan beserta warga masyarakat dan juga menghindari perbedaan pemahaman/persepsi para pegawai dinas pemerintahan beserta masyarakat atas knowledge penting yang menjadi objek aktivitas knowledge management tersebut. Sistem portal pengetahuan dalam pemerintahan harus memiliki sifat interoperabilitas yaitu kapabilitas dari suatu software dan/atau sistem yang antar mukanya diungkapkan sepenuhnya untuk berinteraksi dan berfungsi dengan produk atau sistem lain. Dapat digunakan pada seluruh platform (windows, IOS, andeoid, LINUX, dll) dan device (laptop, smartphone, tab, d1l), juga memiliki fitur untuk mengawasi, memonitor, dan mengevaluasi kinerja para pegawai dinas pemerintahan".

\section{PENUTUP}

Berdasarkan hasil analisis beserta pembahasan yang telah dilakukan, maka diperoleh kesimpulan sebagai berikut: definisi formal ilmiah terstruktur dari sistem portal pengetahuan dalam suatu pemerintahan berhasil didapatkan. Rekomendasi yang dapat diberikan berdasarkan hasil penelitian adalah dapat dilakukannya penelitian lanjutan terkait dengan rancangan sistem portal pengetahuan dalam pemerintahan. Rancangan ini mencakup model konseptual, fitur-fitur, serta arsitektur sistem portal pengetahuan dalam pemerintahan tersebut.

\section{DAFTAR PUSTAKA}

[1] Ajmi, D.N. and Iriyadi, I., 2018. Analisis Penentuan Tarif Rawat Inap dan Perhitungan Harga Pokok Pada Klinik Utama Rawat Inap dr.

[2] Akbar, B., Aziz, H.A., Djazuli, A., Kowi, M. and Amyar, F., 2018, February. Performance Effectiveness Measurement of Village Funding Management Using Fuzzy Inference System (FIS) Method. In Conference Proceedings Jakarta Indonesia, ICABE 2018.

[3] Ariffin, M. and Sastra, H., 2020. Pelatihan Peningkatan Pengetahuan Tentang Pembukuan Keuangan Dan Laporan Keuangan Bagi Karyawan PT. Mahatani Di Kota Bogor. Jurnal Abdimas Dedikasi Kesatuan, 1(2), pp.138-148.

[4] H. Al-Hashedi., M. Rafie., M. Arshad., A. S. Baharudin and H. H. Mohamed. (2013). RFID Applications in Hajj Management System.

[5] Becerra, I., Fernandez., Sabherwal, R. (2015). Knowledge Management Systems and Process, Second Edition. New York: Routledge.

[6] Bone, A. (2005). Multi-Agent System Sebagai Solusi Pembangunan Perangkat Lunak Dalam Menjamin Keberlangsungan Hidup Perangkat Lunak. In 2005 Seminar Nasional Aplikasi Teknologi Informasi (SNATI). Yogyakarta.

[7] Cahyaningsih, E., Sensuse, Dana., Wibowo, Catur., Latifah, Retnany., Sari, Wina, (2016). NUSANTARA: A New Design of Knowledge Management System in Indonesia. In 2016 International Conference on Information Technology System and Innovation (ICITSI) Bandung - Bali, November 24 - 27, 2016. Indonesia. 
[8] EIKheshin, S., Saleeb, N. (2016). A Conceptual Model for E-government Adoption in Egypt. In 2016 11th International Conference on Computer Engineering \& Systems (ICCES). Egypt.

[9] Fauzie, A., Budi, I., Sensuse, D., Imanda, R., Satria, W., Catur, W. (2016) Definition of e-Hajj in Indonesia using Hermeneutic Approach. In 2016 IEEE Student Conference on Research and Development (SCORED). Malaysia.

[10] Firdaus, O., Suryadi, K.., Govindaraju, R.., Samadhi, A. (2012). Knowledge Sharing Model Development in Community of Practice (CoP) Among Doctors. In 2012 IEEE International Conference on Management of Innovation \& Technology (ICMIT). Indonesia.

[11] Gendalasari, G.G., 2020. A Market-Based analysis On Small and A Medium Busines Strategies in Bogor's Footwear Industry. Riset, 2(1), pp.153-166.

[12] Hidayatullah, H. (2011). SSM, Sebuah Pendekatan Holistik untuk Kegiatan Aksi (Learning for Actions). In Jurnal Sosiologi Islam Vol. 1 No. 2.

[13] Hidayat, L., Muktiadji, N. and Supriadi, Y., 2020, May. The Knowledge and Students' Interest to Investing in Investment Gallery. In 2nd International Seminar on Business, Economics, Social Science and Technology (ISBEST 2019) (pp. 142-145).

[14] Ismail, A., Sulaiman, S. (2011). Model for Knowledge Portal to Support Communities of Practice. In 2011 Malaysian Conference in Software Engineering. Malaysia.

[15] K. J. Friston and C. D. Frith. (2015). Active Inference, Communication and Hermeneutics. Cortex, vol. 68, no. Kelso 2012, pp. 129-143.

[16] Kuryadi, K.V. and Andrianto, T., 2018. The Effect of Inter-Period Tax Allocation Based on PSAK No. 46 on The Coefficient of Accounting Profit Response. In International Conference On Accounting And Management Science 2018 (pp. 281-281).

[17] Kwjnckw, R.., Tickle, M., Morton, S. (2010). Online Communities of Practice for innovation and knowledge transfer: A case study in the U.K. In 2010 IEEE International Conference on Management of Innovation \& Technology. Singapore.

[18] M. Jennings. (2016). Potential Barriers to The Competence Assesment of Offshore Installation Manager: A Hermeneutic Perspective., JLoss Prev. Process Ind., vol 44, no. April 201, pp. 132-142.

[19] Marlina, T., Danial, M. and Susmiatik, S., 2015. Peranan Sistem Penjualan Dalam Kaitannya Dengan Kolektibilitas Piutang. Jurnal Ilmiah Akuntansi Kesatuan, 3(3), pp.168-180.

[20] Merlina, M. and Nuraini, A., 2020. Analisis Persepsi Dosen Akuntansi Dan Mahasiswa Akuntansi Mengenai Peranan Akuntan Di Era Revolusi Industri 4.0. JAS-PT (Jurnal Analisis Sistem Pendidikan Tinggi Indonesia), 4(2), pp.149-162.

[21] Mulyana, M., 2012. Consumer Behaviour: Sukses Dengan Memahami Konsumen.

[22] Peraturan Menteri Negara Pendayagunaan Aparatur Negara dan Reformasi Birokrasi Tahun 2011 Nomor 14.

[23] Ramadhan, A., Muladno., Sensuse, D., Arymurthy, A., (2012). e-Livestock in Indonesia: Definition Adjustment, Expected Benefits, and Challenges. In 2012 International Conference on Advanced Computer Science and Information Systems (ICACSIS). Indonesia.

[24] Ramadhan, A., Sensuse, D., Arymurthy, A., (2011). A Proposed Methodology to Develop an e-Government System Based on Soft Systems Methodology (SSM) and Focus Group Discussion (FGD). In 2011 International Conference on Advanced Computer Science and Information Systems. Indonesia.

[25] Razali, S., Noor, N., Laila, A., Wan, A. (2010). Applying Soft System Methodology (SSM) into the Design Science: Conceptual Modeling of Community based Emuseum (ComE) Framework. In 2010 IEEE International Conference on Systems, Man and Cybernetics. Turkey.

[26] Ribera, S., Canabate, A., Botella, A., Casanovas, J. (2011). e-Catalunya an egovernment service for virtual Communities of Practice. In 2011 Annual SRII Global Conference. USA. 
Knowledge Management System

[27] S. Sarker and A. S. Lee. (2006). Does The Use of Computer-Based BPC Tools Contribute to Redesign Effectiveness? Insight from A Hermeneutic Study. Vol. 53. No 1. pp. 130-145.

[28] Sudradjat, S., Ahmar, N. and Mulyadi, J.M.V., 2017. Pengaruh Leverage, Arus kas Operasi, Ukuran Perusahaan dan Fixed Asset Intensity terhadap Keputusan Revaluasi Aset tetap (Studi Empiris pada Bank Umum yang Terdaftar di BEI Periode 2012 sd 2016). Jurnal Ilmiah Akuntansi Kesatuan, 5(2), pp.129-142.

[29] Suwarno, S., 2019. Pengelolaan keuangan desa: Perencanaan sampai dengan Pertanggungjawaban pada desa di Kecamatan Cilongok Banyumas. Jurnal Riset Akuntansi \& Perpajakan (JRAP), 6(01).

[30] Undang-Undang Tahun 2014 Republik Indonesia Nomor 5. 